\title{
Leadership Styles and Talent Retention from Higher Education Institutions in Viet Nam A Conceptual Framework
}

\author{
Bui Thi Hoang Truyen \\ Property and Engineering Department \\ Saigon Post-Telecommunication Insurance Company \\ Ho Chi Minh, Viet Nam \\ truyenbui82.ck28@st.ueh.edu.vn
}

\author{
Nguyen Phu Phuong Trang \\ Faculty of Aviation Economics \\ Viet Nam Aviation Academy \\ Ho Chi Minh, Viet Nam \\ trangnpp@vaa.edu.vn
}

\begin{abstract}
In recent years, several universities have implemented the accomplishments of the industrial revolution (4.0) in education. This demonstrates the importance of talent retention in the workplace, and brilliant individuals are seen as one of competitive advantage. Managers should have suitable talent management plans because talented individuals are scarce, valuable, and hard to substitute. Through the characteristics that leadership styles will affect, such as reward and recognition, learning orientation, and organizational justice, it will provide the organization with a perspective on the members' feelings about the factors affecting the intention to work longterm at higher education institutions. As a result, the authors propose exploring the talent retention model through leadership styles, which will impact the aspects that employees in an organization feel would be interesting and relevant to them. The authors to guide this study will conduct two phases: qualitative research and quantitative research. To investigate the fundamental factors of leadership style behavior, relating to the talent retention strategy of university leaders in Vietnam, qualitative research will be conducted on 8 universities in three regions. North, Central, and South of Vietnam by semi-structured interview method after interview questions with 8 leaders representing higher education institutions. Quantitative research will be conducted by gathering data from lecturers, researchers from organizations in order to test hypotheses based on the findings of qualitative research.
\end{abstract}

Index Terms-Leadership styles, talent retention, reward and recognition, learning orientation, organizational justice.

\section{INTRODUCTION}

$\mathrm{L}$ EADERSHIP is frequently mentioned in human re${ }_{\text {source management as a vital aspect in retaining talent }}$ [1]. The leader or manager must have in his hand an important weapon: a suitable leadership style that allows him to fulfill both the demands of employees and the needs of the employee's personal and organizational strengths. There are many elements that influence talent attraction and retention, but the two most essential sets of factors that each organization must pay special attention to are factors connected to the organization and its group of people [2]. Employee retention depends on the role of leadership and supervision, argues that employees leave managers, not the organization [3]. As a result, in order to be successful in its operations, a company must place a premium on the human component.

In today's educational environment, lecturers are a group of highly educated individuals who teach as well as conduct research. As a result, higher education institutions are continually on the lookout for individuals who can contribute to both the organization's performance and the educational knowledge treasure. Many recent researches have found that type of leadership such as transformational leadership and transactional leadership have a significant positive impact on lecturers' work satisfaction [4]. Lecturer job satisfaction is linked to retention in a number of ways, including satisfaction with university leadership [5]. Much prior research has demonstrated that leadership behavior has separate effects on rewards and recognition (RAR), organizational justice (OJ), and learning orientation (LO) and, revealing it as a factor influencing the decision to work at an organization for a long time.

Although the terms "leadership" and "talent retention" have been researched for decades and in a variety of sectors, leadership and retention of talent in higher education organizations is a relatively new subject of research that has received little attention. Furthermore, throughout the protracted impact of the covid-19 pandemic, higher education institutions will face a challenge in determining a more appropriate leadership style to guide the development of employees and organizations. The author's intent in this study is to propose an exploratory model and explore the role of RAR, OJ, and LO as intermediate variables in order to confirm the strong impact of two leadership styles on activities connected to the organization's talent retention. The study focuses on the leadership behavior of leaders in higher education institutions to address this issue. The authors intend to increase knowledge of higher education leadership and present new findings on the leadership behavior's impact on strategic success in retaining talent in higher education institutions. The current study's goal was to look at the impact of two elements on talent retention from their employment: the impact of leadership styles (transformational or transactional) and the mediating roles of reward and recognition, organizational justice, and learning orientation in university.

\section{Literature ReVIEW}

\section{A. Leadership styles and talent retention}

Reference [6], leadership is the art of inspiring and assisting others to accomplish things on their own initiative, rather than because they have been asked or are terrified of the repercussions of non-compliance. Influential leadership does not imply that the leader has the ability to manage or direct personnel toward the goals that the leader desires; rather, the results are influenced by the leader's activities. employee ac- 
tivities and conduct [7]. Research on employee talent retention strategies by [8] indicates that the decision of employees to engage with the organization is often strongly related to the type of leadership. This research proposes to investigate the role of different leadership styles in influencing talent retention including two styles transformational leadership and transactional leadership. Transactional leadership is defined by an exchange process in which followers comply with the leader's demands but fail to raise in inspiration and dedication for a mission goal. [9]. On the other hand, according to [10] transformational leadership is where the leader inspires, motivates, and encourages subordinates to always be determined and passionate about their work. Previous research has highlighted the link between transformational leadership and talent retention. $[11,12,13]$.

This study uses the Multifactor Leadership Questionnaire (MLQ-5X) as the specific tool to evaluate the behavior for transformational and transactional leadership models [14]. The Multifactor Leadership Questionnaire (MLQ-5X) has been translated into many languages and used by scholars in their research around the world. In which, MLQ-5X evaluates the behavior of transformational leadership based on 5 aspects including, idealized influence attributed; idealized influence behavior; inspirational motivation, individualized consideration and intellectual stimulation. In contrast, MLQ$5 \mathrm{X}$ evaluates transactional leadership on four dimensions including laissez-faire; contingent reward; passive management by exception; active management by exception. One of the most essential concerns in today's organizations is retaining competent people. According to [15], The loss of highly competent and well-trained employees is the most significant cost associated with employee turnover. These expenses include recruitment expenditures as well as other expenses made by the company to guarantee that a substitute employee is properly addressed and developed inside the company [16]. In the field of education, especially in higher education, organizations are always looking for talented graduates from home and abroad or with high academic qualifications to work at universities. Therefore, retaining talent, even more, emphasizes its role after attracting talent to work for the organization. Organizations can have measures to attract talent, but it does not mean that they will retain talented people who are committed to the organization in the long run.

\section{B. Leadership styles and talent retention through mediating role reward and recognition}

Individuals are motivated to work better in the organization when they are rewarded and recognized. Whereas, compliments, group celebrations, and written acknowledgment are some examples of non-monetary rewards that might benefit a group or team formation [17]. When an organization has a good reward system in place, the employee is motivated to achieve high-level organizational goals, who feel safe and know that continual learning and career advancement are valued and encouraged [18]. According to, managers should build and implement efficient reward and recognition systems for individuals to establish a balance between mutual aims, keeping employees with high morale to encourage optimal organizational performance [19], [20]. Furthermore, a number of academic studies have found that motivation, reward, recognition, passion, and effective talent management are some of the factors that leaders consider to be effective businesses must address in order to mitigate turnover rate and retain talented employees in the organization. [21]. Through previous studies, we have clarified the impression in a type of leadership on reward and recognition and shown the correlation between reward and recognition and talent retention. This study proposes to examine the mediating correlation between the type of leadership and talent retention through reward and recognition.

\section{Leadership styles and talent retention through mediating role organizational justice}

One of management's most essential responsibilities is to establish a positive work environment for employees, which influences their decision to commit and stay with the company even when alternative job prospects exist outside of it. [22]. Equity in the organization is demonstrated as the employee's perception of the perceived fairness that occurs in the organization [23]. It is very important to perceive something that feels fair or unfair to an employee, which will affect employee behavior i.e., desire to leave a job, job satisfaction of employees, commitment to work, and participation in work [11]. There are many approaches to aspects of organizational justice, but in this study, the authors will exploit organizational justice from three aspects: interactional justice, distributive justice, and procedural justice. Procedural Justice addresses perceptions regarding the fair rules and procedures governing a process [24]. The existence of this type of justice makes satisfaction with the organization [25], [26]. The perception of fairness is referred to as interactional justice in treating individuals with each other [20]. It has to do with people's perceptions of compassion and respect when making conclusions and looking at information. [27]. Distributive justice addresses employees' perceptions of the fairness of the reward system [20]. Compared to other employees, an employee must believe that awards are distributed fairly and without discrimination, i.e. in proportion to their point of giving and effort. [28]. In particular, the authors believe that in an academic environment, employees are considered as one of the most knowledgeable and highly qualified workers, therefore, the perception of organizational justice plays an important role in employing and retaining people of the organization. Highly qualified workers, especially in the field of education such as lecturers, will tend to move to other educational institutions if they do not feel organizational justice because they have enough knowledge and sensitivity to feel it justice where they work. Through previous studies, we have clarified the influence of the type of leadership and organizational justice [29] and showed the correlation between organizational justice and talent retention [24], [30]. This study proposes to examine the mediating role between leadership styles to talent retention through organizational justice.

\section{Leadership styles and talent retention through mediating role learning orientation}

Learning orientation is defined as a fundamental attitude toward learning, as well as organizational and managerial traits that support learning in the organization. [25]. Learning orientation provides potentially behavior-changing insights 
[31] by impressing employees with their aspiration to continuously build up and broaden their knowledge and abilities [32]. Organizations want to keep their employees, it's critical to pay attention to their learning and development goals. Allowing employees to do more and learn more of what they excel at motivates them to stay with the company. [33]. Higher education institutions are places where the learning orientation of workers should be taken into account. Lecturers are subjects who both play two important roles: teaching and research. Therefore, the study orientation for this group of workers is aimed at expanding knowledge, improving expertise in teaching, and supporting lecturers in conducting research. Learning orientation is measured from four dimensions including shared vision, intra-organizational knowledge-sharing, commitment to learning and open-mindedness, and [34], [35].

Leadership has an important role in sharing organizational learning, acquiring new knowledge, and applying this knowledge to improve organizational performance [36]. Leadership creates an atmosphere of openness and mental safety for organizational learning [37], [38], [39]. By modeling learning behavior, encouraging employees to offer new ideas, and assuring knowledge distribution to stimulate creativity, transformational leaders provide critical support to employee learning and growth. Transformational leaders treat employees as independent individuals who show interest in their employees' unique problems and approaches to work and create opportunities for growth. They transfer autonomy to their staff and use their superior knowledge and expertise to help them grow. [40]. A positive association between transactional leadership style and organizational learning has been found in several researches [41], [42] , [43]. There's a point illustrating that transactional leadership behaviors improve and extend existing knowledge structures [42]. However, other studies have shown a negative correlation between transactional leadership and learning [44].

In addition, a number of researches have also shown the relationship between learning orientation affecting talent retention, arguing that this is one of the vital elements for retaining talent in organizations [45]. Through previous studies, we have clarified the influence of the style of leadership on learning orientation and showed the correlation between learning orientation and talent retention. This study proposes to examine the mediating role between leadership styles to talent retention through learning orientation.

From theoretical arguments, the authors propose to study the leadership styles relationship model to talent retention through testing the mediating role of the following three components: reward and recognition, organizational justice, learning orientation. In which leadership styles include transformational leadership and transactional leadership.

\section{Research Methodology}

This study aimed to explore leadership styles that impact talent retention through exploring mediating effects including reward and recognition, organizational justice, learning orientation. By using a multifactor leadership questionnaire (MLQ) to explore the behavior of two types of leaders. The scale has five factors for transformational leadership including idealized influence attributed; idealized influence behav-

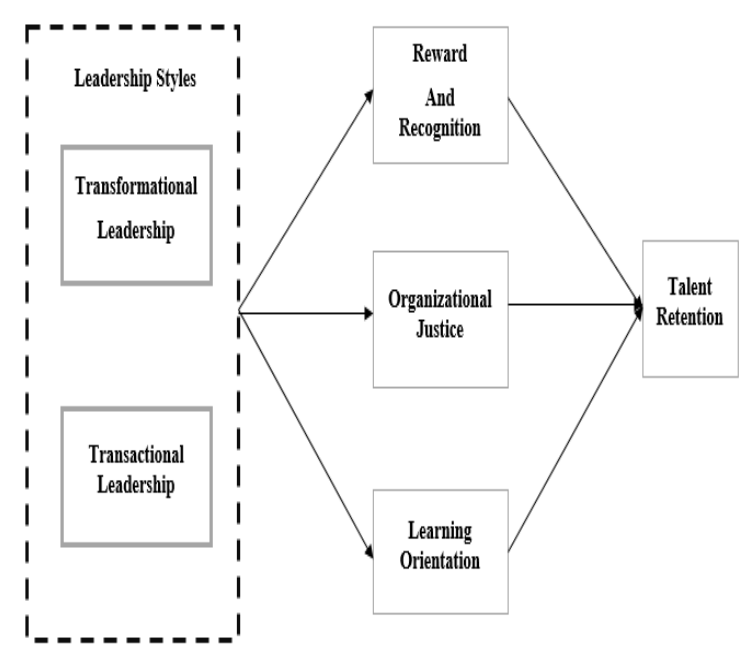

Fig.1.Conceptual Framework

ior; inspirational motivation, individualized consideration and intellectual stimulation. [46]. The scale has four factors for transactional leadership: contingent reward; active management by exception; passive management by exception; laissez-faire [46]. Research is divided into two processes including qualitative research and quantitative research. Qualitative research explores how leadership styles influence talent retention. Quantitative research based on qualitative research is conducted based on a formal questionnaire with the form of data collection from the responders who meet the conditions before entering the official data collection to meet the level of satisfaction exactly that the research scope of the topic is formed. In addition, quantitative research will test the relationships proposed in the research model through support tools.

\section{A. Qualitative Research}

Although there are many ways to collect data in qualitative research, according to [47], the in-depth interview method is the method used mainly and popularly in qualitative research. An in-depth interview is an exchange of views between two people on an issue, in which the interviewer tries to understand the issue based on the interviewee's point of view. The semi-structured question-based in-depth interview method gives the interviewer the freedom to dive deeply into the responders' thoughts, feelings, and motives in relation to the study problem [48]. On the other hand, it helps naturalize the interview, enabling responders to express their experiences, ideas, and feelings more honestly.

Purposeful sampling is the purposeful selection of information-rich subjects [49], [50] to assist the researcher in best understanding the research question and phenomenon [47] and enables the researcher to meet the research topic's specific requirements. Therefore, in this study, the authors select the subjects to interview are 10 leaders with 5 years of management experience or more in higher education operating for 5 years or more. The subjects that the authors propose to conduct in-depth interviews should include leaders or managers of both male and female genders, diverse professions, and diverse ages. Through qualitative research, the authors aim to receive sharing from school leaders in talent retention behavior through their organizations. Thereby discovering 
more factors constituting leadership styles, affecting the components considered as important strategies in retaining talent, including reward and recognition, organizational justice, learning orientation.

Potential responders to interview in this research will be selected on the basis of the following classification characteristics: (1) working in higher education institutions (2) experience managing or leading for 5 years or more (3) higher education institutions that have been inactive for more than 10 years. After introducing the content and purpose of the study and receiving the consent of the responders, the researcher will arrange an appointment to conduct an in-depth interview. These interviews will be recorded (with the consent of the responders) to serve the purpose of storing and analyzing more detailed information after these conversations. The recording will be translated into text. On average, each interview lasted about 30 to 45 minutes. The researcher will begin the interview by introducing the purpose of the study and asking the responders to allow the researcher to share the content of the interview. The personal information of the interviewees including names, phone numbers, and email is kept confidential. A list of open-ended questions is used to keep the conversation around the research topic and to ensure all relevant content is covered. At the end of the interview, the researcher acknowledged the responders and asked them to contact them in case of any feedback or retraction of the information provided.

\section{B. Quantitative research}

Quantitative research will be based on elements built from qualitative research and provide a formal questionnaire. Using the convenience method sampling technique for the purpose of collecting data for the purpose of the study, the authors propose to limit the scope of the information collected from employees who include lecturers, researchers, with at least 3 years of working experience in higher education institutions representing three regions of North, Central, and South in Vietnam. With work experience with superiors, the authors approach the interview with the desire to receive open and honest feedback on how responders believe their leadership has influenced talent retention through aspects including reward and recognition, organizational justice, learning orientation. The authors propose to use Likert 7 - point scale ranging from "strongly disagree" to "strongly agree" in the survey collecting data from responders, because it responds better than the actual assessment responder, is easier to use, and provides more data points for the operation of the information system [51].

\section{Conclusion}

The authors propose to study the impact model between leadership styles on talent retention by examining the mediating roles of reward and recognition, organizational justice, learning orientation to emphasize the role of leadership styles on their behavior. After empirical research takes place, it will create scientific value and implications for practitioners. That helps leaders at universities have the right orientation in the strategy of talent retention through results of research. Empirical research will explore the correlation between leadership style and talent retention to show the mediating effects that a leader needs to make to retain talent in a higher education institution. However, the limitation of the model is that it has not exploited all aspects based on the characteristics constituting leadership styles, the model only clarifies the impact between leadership styles on talent retention through mediating roles. Future framework research is proposed to explore more factors affecting talent retention that this study has not mentioned. In addition, the future research model should coordinate to explore the role of demographic variables that play the role of moderator variables in the model. Furthermore, the function of mediator factors can be investigated to elucidate the level of influence between the components.

\section{REFERENCES}

[1] B. Meyer et al., "What good leaders actually do: micro-level leadership behaviour, leader evaluations, and team decision quality," Eur. J. Work Organ. Psychol., vol. 25, no. 6, pp. 773-789, 2016, doi: 10.1080/1359432X.2016.1189903.

[2] B. L. Das and M. Baruah, "Employee Retention: A Review of Literature," IOSR J. Bus. Manag., vol. 14, no. 2, pp. 08-16, 2013, doi: $10.9790 / 487 \mathrm{x}-1420816$.

[3] I. Journal, "Reflections on the determinants of voluntary turnover," Int. J. Manpow., vol. 22, no. 7, pp. 600-624, 2000.

[4] Y. N. Azizah et al., "Transformational or transactional leadership style: Which affects work satisfaction and performance of islamic university lecturers during COVID-19 pandemic?," Syst. Rev. Pharm., vol. 11, no. 7, pp. 577-588, 2020, doi: 10.31838/srp.2020.7.82.

[5] M. Betancourt-Smith, D. Inman, and L. Marlow, "Professional Attrition: An Examination of Minority and Nonminority Teachers AtRisk," Pap. Annu. Meet. Mid-South Educ. Res. Assoc. Nashville, TN, pp. $1-10,1994$.

[6] J. A. Okumbe, Educational Management: Theory and Practice. African Books Collective Ltd.: The Jam Factory, 27 Park End Street, Oxford OX1 1HU, United Kingdom, 1998.

[7] B. M. Wakabi, "Leadership Style and Staff Retention in Organisations," Int. J. Sci. Res., vol. 5, no. 1, pp. 412-416, 2016, doi: 10.21275/v5i1.nov152642.

[8] J. Zhang, M. F. Ahammad, S. Tarba, C. L. Cooper, K. W. Glaister, and J. Wang, "The effect of leadership style on talent retention during Merger and Acquisition integration: evidence from China," Int. J. Hum. Resour. Manag., vol. 26, no. 7, pp. 1021-1050, 2015, doi: 10.1080/09585192.2014.908316.

[9] N. Izidor and I. E B J, "Nexus Between Leadership Styles, Employee Retention and Performance in Organizations in Nigeria," Eur. Sci. J., vol. 11, no. 13, pp. 185-209, 2015.

[10] K. Nielsen, J. Yarker, S. O. Brenner, R. Randall, and V. Borg, "The importance of transformational leadership style for the well-being of employees working with older people," J. Adv. Nurs., vol. 63, no. 5, pp. 465-475, 2008, doi: 10.1111/j.1365-2648.2008.04701.x.

[11] M. A. Y. Yamin, "Examining the role of transformational leadership and entrepreneurial orientation on employee retention with moderating role of competitive advantage," Manag. Sci. Lett., vol. 10, no. 2, pp. 313-326, 2020, doi: 10.5267/j.msl.2019.8.039.

[12] Á. R. Para González, Lorena; Jiménez Jiménez, Daniel; Martínez Lorente, "Exploring the Mediating Effects Between Transformational," Empl. Relations, vol. 40, no. 2, pp. 412-432, 2018, [Online]. Available: https://doi.org/10.1108/ER-10-2016-0190.

[13] X. Yizhong, Y. Baranchenko, Z. Lin, C. K. Lau, and J. Ma, "The influences of transformational leadership on employee employability: Evidence from China," Empl. Relations, 2019.

[14] B. M. Bass and B. J. Avolio, MLQ, Multifactor Leadership Questionnaire sampler set: technical report, leader form, rater form, and scoring key for MLQ form 5x-short, 2nd ed. Redwood City, CA.: Mind Garden, (C)2000, 2000.

[15] S. Makhubela and M. Ngoepe, "Knowledge retention in a platinum mine in the North West Province of South Africa," SA J. Inf. Manag., vol. 20, no. 1, pp. 1-8, 2018, doi: 10.4102/sajim.v20i1.905.

[16] M. R. Mey, P. Poisat, and C. Stindt, "The influence of leadership behaviours on talent retention: An empirical study," SA J. Hum. Resour. Manag., vol. 19, pp. 1-9, 2021, doi: 10.4102/sajhrm.v19i0.1504.

[17] R. Cacioppe, "Using team - individual reward and recognition strategies to drive organizational success," Leadersh. Organ. Dev. J., vol. 20, no. 6, pp. 322-331, 1999, doi: 10.1108/01437739910292634. 
[18] S. C. Bushardt, D. W. Glascoff, and D. Harold Doty, "Organizational culture, formal reward structure, and effective strategy implementation: A conceptual model," J. Organ. Cult. Commun. Confl., vol. 15 , no. 2 , pp. 57-70, 2011.

[19] P. M. Koech and G. Namusonge, "The Effect of Leadership Styles on Organizational Performance at State Corporations in Kenya," Int. J. Bus. Commer., vol. 2, no. 1, pp. 1-12, 2012, [Online]. Available: www.ijbcnet.com.

[20] S. C. Selden and J. E. Sowa, "Voluntary Turnover in Nonprofit Human Service Organizations: The Impact of High Performance Work Practices," Hum. Serv. Organ. Manag. Leadersh. Gov., vol. 39, no. 3, pp. 182-207, 2015, doi: 10.1080/23303131.2015.1031416.

[21] N. Mngomezulu, M. Challenor, E. Munapo, P. Mashau, and C. Chikandiwa, "The impact of recognition on retention of good talent in the workforce," J. Gov. Regul., vol. 4, no. 4, pp. 372-379, 2015, doi: 10.22495/jgr_v4_i4_c3_p2.

[22] S. Michael, "Using Motivational Strategy as Panacea for Employee Retention and Turnover in Selected Public and Private Sector Organisations in the Eastern Cape Province of South Africa," University of Fort Hare, 2008.

[23] N. Silitonga et al., "The Relationship of Transformational Leadership, Organizational Justice and Organizational Commitment: a Mediation Effect of Job Satisfaction," J. Crit. Rev., vol. 7, no. 19, pp. 89-108, 2020, [Online]. Available: http://www.jcreview.com/?mno=101999.

[24] R. Imran and K. Allil, "The impact of organizational justice on employee retention: Evidence from Oman," Int. Rev. Manag. Mark., vol. 6, no. 2, pp. 246-249, 2016.

[25] A. Fatima, R. Imran, H. Shahab, and S. Zulfi qar, "Knowledge sharing among Pakistani IT professionals: Examining the role of procedura justice, pay satisfaction and organizational commitment," $A d v$. Sci. Lett., vol. 21, no. 5, pp. 1189-1192, 2015.

[26] T. Nabatchi, L. B. Bingham, and D. H. Good, "Organizational justice and workplace mediation: A six-factor model," Int. J. Confl. Manag., vol. 18, no. 2, pp. 148-174, 2007, doi: 10.1108/10444060710759354.

[27] R. Bies and J. . Moag, "Interactional justice: Communication criteria of fairness," Res. Negot. Organ., vol. 1, no. 1, pp. 43-55, 1986.

[28] M. Alsalem and A. Alhaiani, "Relationship between organizational justice and employees performance," Aledari, vol. 108, pp. 97-110, 2007.

[29] N. Gillet, E. Fouquereau, A. Bonnaud-Antignac, R. Mokounkolo, and P. Colombat, "The mediating role of organizational justice in the relationship between transformational leadership and nurses' quality of work life: A cross-sectional questionnaire survey," Int. J. Nurs. Stud., vol. 50, no. 10, pp. 1359-1367, 2013, doi: 10.1016/ j.ijnurstu.2012.12.012.

[30] R. A. Gohar and Q. A. Qureshi, "Connecting Talent Management and Employees' Retention: A Mediating Role of Organizational Justice," City Univ. Res. J., no. 11, pp. 124-143, 2021, [Online]. Available: https://search.proquest.com/openview/a06bd74f95dcd1dbd5c8eff90ca $6256 \mathrm{a} / 1$ ?pq-origsite $=$ gscholar\&cbl $=2068970$.

[31] G. P. Huber, "Organizational Learning: The Contributing Processes and the Literatures," Organ. Sci., vol. 2, no. 1, pp. 88-115, 1991, doi: 10.1287/orsc.2.1.88.

[32] A. K. Kohli, T. A. Shervani, and G. N. Challagalla, "Learning and performance orientation of salespeople: The role of supervisors," $J$. Mark. Res., vol. 35, no. 2, pp. 263-274, 1998, doi: 10.2307/3151853.

[33] N. Govaerts, E. Kyndt, F. Dochy, and H. Baert, "Influence of learning and working climate on the retention of talented employees," J. Work. Learn., vol. 23, no. 1, pp. 35-55, 2011, doi $10.1108 / 13665621111097245$.
[34] G. T. M. Hult and O. C. Ferrell, "Global Organizational Learning Capacity in Purchasing: Construct and Measurement," J. Bus. Res., vol. 2963, no. 96, pp. 97-111, 1997.

[35] R. F. Hurley and G. T. M. Hult, "Innovation, market orientation, and organizational learning: An integration and empirical examination," $J$. Mark., vol. 62, no. 3, pp. 42-54, 1998, doi: 10.2307/1251742.

[36] B. Khalifa and R. M. Ayoubi, "Leadership styles at Syrian higher education: What matters for organizational learning at public and private universities?," Int. J. Educ. Manag., vol. 29, no. 4, pp. 477491, 2015, doi: 10.1108/IJEM-03-2014-0036.

[37] Chris Argyris and Donald A. Schön, Organizational learning II: Theory, method and practice Reading, 2nd ed. Reading: Addison Wesley, 1996

[38] A. Edmondson, "Psychological safety and learning behavior in work teams," Adm. Sci. Q., vol. 44, no. 2, pp. 350-383, 1999, doi: $10.2307 / 2666999$.

[39] E. H. Schein, "How can organizations learn faster?: the problem of entering the Green Room,” Japanese Soc. Biofeedback Res., vol. 19, no. Alfred P. Sloan School of Management, Massachusetts Institute of Technology, pp. 709-715, 1992, [Online]. Available: http://hdl.handle.net/1721.1/2399.

[40] T. Dvir, D. Eden, B. J. Avolio, and B. Shamir, "Impact of transformational leadership on follower development and performance: A field experiment," Acad. Manag. J., vol. 45, no. 4, pp. 735-744, 2002, doi: 10.2307/3069307.

[41] A. F. Coad and A. J. Berry, "Transformational leadership and learning orientation," Leadersh. Organ. Dev. J., vol. 19, no. 3, pp. 164-172, 1998, doi: 10.1108/01437739810210211.

[42] J. J. P. Jansen, D. Vera, and M. Crossan, "Strategic leadership for exploration and exploitation: The moderating role of environmental dynamism," Leadersh. Q., vol. 20, no. 1, pp. 5-18, 2009, doi: 10.1016/j.leaqua.2008.11.008.

[43] W. A. Nafei, N. M. Khanfar, and B. A. Kaifi, "Leadership Styles and Organizational Learning An Empirical Study on Saudi Banks in AlTaif Governorate Kingdom of Saudi Arabia," J. Manag. Strateg., vol. 3, no. 1 , pp. 2-17, 2012, doi: 10.5430/jms.v3n1p2.

[44] M. Amitay, M. Popper, and R. Lipshitz, "Leadership styles and organizational learning in community clinics," Learn. Organ., vol. 12, no. 1, pp. 57-70, 2005, doi: 10.1108/09696470510574269.

[45] A. D'Amato and R. Herzfeldt, "Learning orientation, organizational commitment and talent retention across generations: A study of European managers," J. Manag. Psychol., vol. 23, no. 8, pp. 929-953, 2008, doi: $10.1108 / 02683940810904402$.

[46] J. Rowold, "Multifactor Leadership Questionnaire," Psychom. Prop. Ger. Transl. by Jens Rowold, no. Mind Garden, 2005.

[47] J. W. Creswell, Qualitative, quantitative and mixed methods approaches, 4th ed. Thousand Oaks: Sage, 2014.

[48] D. M. Tran, W. Fallon, and M. H. Vickers, "Leadership in Vietnamese state owned enterprises (SOEs): Exploring multi-stakeholder perceptions-a qualitative study," Asia-Pacific J. Bus. Adm., vol. 8, no. 1, pp. 21-36, 2016, doi: doi.org/10.1108/APJBA-10-2014-0116.

[49] M. Patton, Qualitative research and evaluation methods. London: Sage Publications, 1978.

[50] J. Ritchie, J. Lewis, C. . Nicholls, and R. Ormston, Qualitative research practice: A guide for social science students and researchers. Los Angeles, California: Sage, 2013.

[51] A. Joshi, S. Kale, S. Chandel, and D. Pal, "Likert Scale: Explored and Explained," Br. J. Appl. Sci. Technol., vol. 7, no. 4, pp. 396-403, 2015, doi: 10.9734/bjast/2015/14975. 